\title{
Efeito de revestimentos comestíveis na conservação de mamões minimamente processados
}

\author{
Effect of edible coatings on the preservation of fresh cut papayas
}

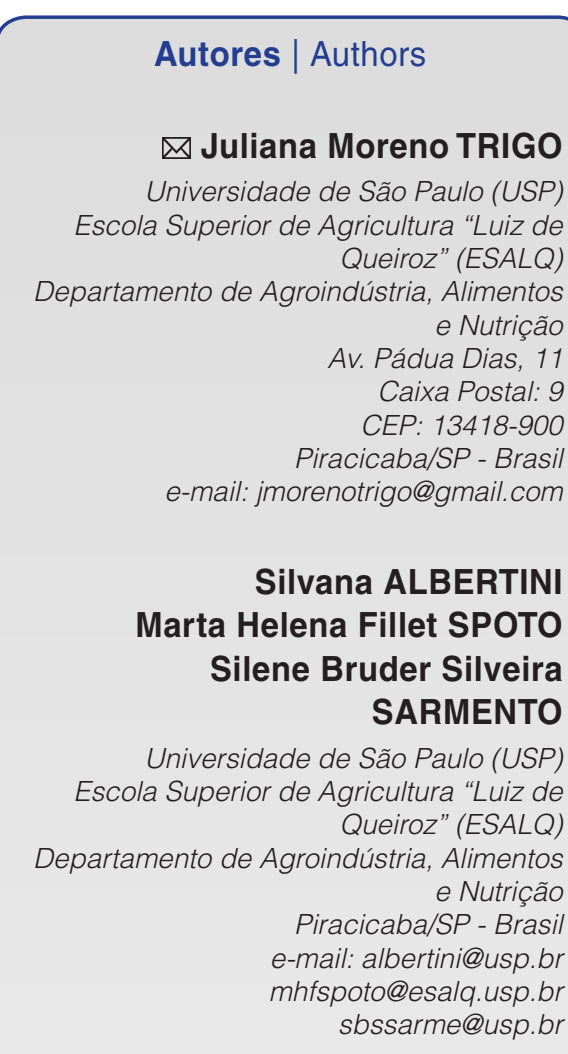

\section{Andrés Enrique LAI REYES}

Universidade de São Paulo (USP) Escola Superior de Agricultura "Luiz de Queiroz" (ESALQ) Seção Técnica de Informática Piracicaba/SP - Brasil e-mail: lai@usp.br

\section{Gabriel Adrián SARRIÉS}

Universidade de São Paulo (USP) Escola Superior de Agricultura "Luiz de Queiroz" (ESALQ)

Departamento de Ciências Exatas Piracicaba/SP - Brasil e-mail:gabriel@esalq.usp.br

$\triangle$ Autor Correspondente / Corresponding Author

Recebido / Received: 22/03/2011 Aprovado / Approved: 05/12/2011 Publicado / Published: jun./2012
Resumo

Avaliou-se o efeito de revestimentos à base de carboidratos nas características microbiológicas, físicas, físico-químicas e sensoriais de mamão Formosa minimamente processado (MP), armazenado sob refrigeração. Após tratamento com cloreto de cálcio, os frutos descascados e cortados foram imersos em soluções de amido de arroz (AA) 3\%; alginato de sódio (AS) 0,5\%; carboximetilcelulose (CMC) 0,25\%, e armazenados a $5{ }^{\circ} \mathrm{C}$ e $90 \%$ de UR. Os produtos foram avaliados nos dias 1, 3, 6, 9, 12 e 15. O uso de revestimentos à base de AA, AS e CMC em mamões MP resultou em menor contagem de coliformes totais que o controle. Mamões revestidos com AA e CMC apresentaram redução e aumento do processo respiratório, respectivamente. Os frutos revestidos apresentaram menores teores de sólidos solúveis e seus valores de $\mathrm{pH}$ se tornaram menores após o $9^{\circ}$ dia de armazenamento. O uso da CMC como revestimento proporcionou, no $15^{\circ}$ dia, maior firmeza da polpa. As variações nos parâmetros de cor (Luminosidade, Hue e Croma) não comprometeram a qualidade sensorial do mamão MP. Os atributos sensoriais dos mamões com revestimentos não diferiram do controle durante os 15 dias de estudo. Como a maioria dos efeitos positivos das coberturas ocorreu aos $12^{\circ}$ e $15^{\circ}$ dias e, considerando-se o custo da tecnologia e o preço dos revestimentos, a melhor opção, até 9 dias de armazenamento, consiste em apenas sanitizar os frutos, como feito no controle. Se o interesse for preservar a vida útil por um período maior, até 15 dias, os revestimentos utilizados podem ter resultados satisfatórios, desde que respeitadas as condições de estocagem utilizadas no estudo.

Palavras-chave: Amido; Alginato; Carboximetilcelulose; Carica papaya L.; Pós-colheita.

\section{Summary}

The experiment evaluated the effects of carbohydrate-based coatings on the microbiological, physical, physical-chemical and sensory properties of the fresh cut (FC) Formosa papaya stored under refrigeration. After treatment with calcium chloride, peeled and sliced portions of the fruit were immersed in $3.0 \%$ rice starch (RS), $0.5 \%$ sodium alginate (SA) and $0.25 \%$ carboxymethylcellulose (CMC) solutions, and stored at $5{ }^{\circ} \mathrm{C}$ and $90 \% \mathrm{RH}$. The products were assessed after 1,3 , 6, 9, 12 and 15 days of storage. The use of the RS, SA and CMC-based coatings for TC papaya resulted in lower total coliform counts than presented by the control sample. The papaya coated with RS and CMC showed decreased and increased respiration rates, respectively. The coated samples showed lower soluble solid contents, with decreased $\mathrm{pH}$ values after storage day 9, and the use of CMC as a coating resulted in increased pulp firmness on day 15. Variations in the colour parameters (Luminosity, Hue and Chroma) did not compromise the sensory quality of the TC papaya, and the sensory attributes of the coated samples did not differ from the control samples throughout the 15 days of experimentation. Since most of the positive results were shown on days 12 and 15, and considering the costs of this technology and price of the coatings, for periods of up to 9 days the best option consists of simply sanitizing the fruits, as done with the control samples. If aiming to preserve the shelf life of the papaya slices for a longer period of time (namely, up to 15 days), the above coatings may show satisfactory results so long as the storage conditions described here are accurately reproduced.

Key words: Starch; Alginate; Carboxymethylcellulose; Carica papaya L., Post-harvest. 


\section{Introdução}

O mamão é um dos frutos mais cultivados do mundo e seu mercado vem se expandindo em função da boa aceitabilidade e das possibilidades de aproveitamento do mesmo (MENDONÇA et al., 2006). O volume de produção mundial em 2008 foi superior a 9 milhões de $t$, estando o Brasil em segundo lugar no ranking, com 1,9 milhão de t e contribuição de $21 \%$ da oferta mundial (FNP CONSULTORIA \& COMÉRCIO, 2011).

A produção nacional do mamão está baseada em dois grupos, o Formosa e o Havaí. O primeiro, apesar de bem aceito pelo consumidor, é pouco conveniente para uso individual por causa do tamanho grande, além da falta de uniformidade de tamanho e formato (SOUZA et al., 2005). Assim, a tecnologia do processamento mínimo representa uma alternativa para a ampliação do mercado do mamão desse grupo, uma vez que, adequadamente cortado e embalado, possibilita o consumo nos mais diferentes ambientes, além de permitir um melhor aproveitamento e agregar valor ao produto colhido (TEIXEIRA et al., 2001).

Os entraves do processamento mínimo, entretanto, consistem em preservar os atributos de qualidade dos frutos, pois o corte durante o processamento expõe os tecidos celulares, promovendo aumento do metabolismo, da taxa respiratória, da produção de etileno e, consequentemente, redução da vida útil (CHITARRA e CHITARRA, 2005). E, para mamão, que é um fruto climatérico bastante perecível, o emprego do processamento mínimo pode acelerar ainda mais o seu amadurecimento, o qual se completa em uma semana sob condições ambientes.

A extensão da vida útil é uma das metas das pesquisas em processamento mínimo e vários tratamentos têm sido testados, dentre os quais a utilização de atmosfera modificada, tratamento hidrotérmico, aplicação de compostos de cálcio, ceras na superfície do fruto e filmes plásticos, associados ao armazenamento refrigerado (BICALHO, 1998). Mais recentemente, tem sido também avaliado o uso de revestimentos comestíveis sobre os vegetais, que tem como objetivo uma atuação funcional, de preservar a textura e o valor nutricional, reduzir a taxa respiratória e a produção de etileno, e ainda limitar a perda ou o ganho excessivo de água (BALDWIN, 2007). Além disso, por serem elaborados a partir de polímeros naturais, representam uma nova categoria de materiais com alto potencial para preservar o estado fresco de produtos minimamente processados (MP) altamente perecíveis (ASSIS et al., 2008).

Neste trabalho, foram avaliados os efeitos de três tipos de revestimentos comestíveis à base de carboidratos nas características microbiológicas, físicas, físico-químicas e sensoriais de mamão Formosa MP armazenado sob refrigeração.

\section{Material e métodos}

\subsection{Material}

Foram utilizados mamões (Carica papaya L.) Formosa, maduros (70-80\% da casca amarela), provenientes de uma única área de produção do município de Barreiras-BA e adquiridos na CEAGESP - São Paulo-SP, onde passaram por seleção, procurando tornar o lote uniforme quanto ao grau de maturação e à ausência de danos mecânicos ou podridões.

Para os tratamentos iniciais dos frutos, as matériasprimas utilizadas foram o dicloroisocianurato de sódio dihidratado (NaDCC), da Johnson Diversey, e o cloreto de cálcio P. A. dihidratado, marca Vetec, com peso molecular de 147,01. Como formadores de película, foram utilizadas três matérias-primas, com as respectivas características fornecidas pelos fabricantes: amido de arroz com $80 \%$ de carboidratos, $6 \%$ de proteínas, $1,4 \%$ de gorduras totais e 2,4\% de fibra alimentar, adquirido na Cerealista São José, São Paulo-SP; alginato de sódio, Vetec, com umidade máxima de $16 \%$, $\mathrm{pH}\left(1 \%, 20^{\circ} \mathrm{C}\right)$ de 4,0-7,0 e viscosidade $\left(1 \%, 20{ }^{\circ} \mathrm{C}\right)$ de $1000-1300 \mathrm{cP}$, e carboximetilcelulose de sódio, marca Denvercel, com pureza 99,7\% (base seca), grau de substituição de 0,7, umidade de 6,5\%, pH (1\%, $\left.25^{\circ} \mathrm{C}\right)$ de 6,8 e viscosidade $\left(1 \%, 25^{\circ} \mathrm{C}\right)$ de $800 \mathrm{cp}$, a qual foi cedida pela Murta Especialidades Químicas Ltda., Cotia-SP

\subsection{Preparo das soluções filmogênicas}

- Amido de arroz (AA) a 3\%: aquecimento da suspensão de $3 \mathrm{~g}$ de amido/100 mL de água potável e 10\% de sorbitol, em relação à massa de amido, em banho a $85^{\circ} \mathrm{C}$, sob agitação por 3 min.

- Alginato de sódio (AS) a 0,5\%: aquecimento da suspensão de 0,5 g de alginato de sódio/100 mL de água potável em banho a $70^{\circ} \mathrm{C}$, sob agitação constante (FONTES et al., 2008).

- Carboximetilcelulose (CMC) a 0,25\%: aquecimento da suspensão de 0,25 g de carboximetilcelulose/100 mL de água potável e $10 \%$ de sorbitol, em relação à massa de carboximetilcelulose, em banho a $70{ }^{\circ} \mathrm{C}$, sob agitação constante.

\subsection{Processamento}

Os mamões, depois de lavados com detergente neutro e água corrente, foram sanitizados por $10 \mathrm{~min}$ em solução a $5^{\circ} \mathrm{C}$ de NaDCC com $200 \mathrm{mg} \cdot \mathrm{L}^{-1}$ de cloro ativo e mantidos em câmara fria a $12^{\circ} \mathrm{C}$ por $12 \mathrm{~h}$ (SOUZA et al., 2005). Os frutos foram, então, descascados, suas sementes eliminadas e a polpa cortada em rodelas, as 
quais, em seguida, foram divididas ao meio, originando pedaços com aproximadamente $2,5 \mathrm{~cm}$ de espessura (HERNÁNDEZ et al., 2007). Após imersão em NaDCC com $20 \mathrm{mg} \cdot \mathrm{L}^{-1}$ de cloro ativo, os pedaços de mamão foram drenados por 2 min e imersos nas soluções:

- Controle: solução de $\mathrm{CaCl}_{2}$ 0,75\% por 2 min e drenagem por 2 min.

- AA 3\%: solução de $\mathrm{CaCl}_{2} 0,75 \%$ por 2 min, drenagem por 2 min, imersão em solução de amido de arroz 3\% por 2 min e drenagem por 2 min.

- AS 0,5\%: solução de $\mathrm{CaCl}_{2}$ 0,75\% por 2 min, drenagem por 2 min, imersão em solução de alginato de sódio $0,5 \%$ por 2 min e drenagem por 2 min.

- CMC 0,25\%: solução de $\mathrm{CaCl}_{2} 0,75 \%$ por 2 min, drenagem por 2 min, imersão em solução de carboximetilcelulose $0,25 \%$ por 2 min e drenagem por 2 min.

\subsection{Acondicionamento}

Os mamões MP foram acondicionados em bandejas de polipropileno $(220 \times 167 \times 56 \mathrm{~mm})$, as quais foram fechadas com filme de polipropileno biaxialmente orientado de $50 \mu \mathrm{m}$ de espessura, taxa de transmissão de $\mathrm{O}_{2}\left(23{ }^{\circ} \mathrm{C} / 0 \%\right.$ UR) de $785 \mathrm{cc} \cdot \mathrm{m}^{-2} \cdot \mathrm{dia}^{-1}$ e taxa de permeabilidade ao vapor de água $\left(38{ }^{\circ} \mathrm{C} / 90 \%\right.$ UR) de 2,36 g.m $\mathrm{m}^{-2} \cdot \mathrm{dia}^{-1}$. A selagem do filme na bandeja foi realizada em termosseladora semiautomática UIma Packaging Smart 500, na qual a selagem foi realizada por calor e pressão exercidos por um sistema pneumático. A máquina operou com temperatura de selagem regulada em $110{ }^{\circ} \mathrm{C}$ e tempo de solda de $2 \mathrm{~s}$, condições essas determinadas em pré-testes e que possibilitaram o selamento completo do filme nas bandejas. Cada bandeja continha dois pedaços de mamão e peso médio de $150 \mathrm{~g}$. Os produtos foram mantidos em câmara fria a $5 \pm 1{ }^{\circ} \mathrm{C}$ e $90 \pm 5 \%$ UR. Análises microbiológicas, físicas, físicoquímicas e sensoriais foram realizadas nos dias 1, 3, 6 , 9, 12 e 15 de armazenamento.

\subsection{Análises microbiológicas}

A quantificação de coliformes totais e termotolerantes, bactérias psicrotróficas, bolores e leveduras, e a verificação da presença de Salmonella foram efetuadas de acordo com a Instrução Normativa $n^{\circ}$ 62, de 26 de agosto de 2003 (BRASIL, 2003).

\subsection{Análises físicas e físico-químicas}

Em cada tempo de estocagem, a avaliação da concentração de $\mathrm{CO}_{2}$ no interior das embalagens foi resultado de triplicatas (três bandejas e uma leitura por bandeja) e a avaliação das demais variáveis, de nove repetições (três bandejas e três leituras por bandeja). $O$ teor de $\mathrm{CO}_{2}$ foi quantificado por um analisador de gases portátil da marca PBI Dansensor, modelo CheckPoint $\mathrm{O}_{2} /$ $\mathrm{CO}_{2}$. A agulha coletora de gás foi introduzida no espaço livre das embalagens através de septos confeccionados com cola de silicone, filme de polietileno tereftalato e fita adesiva dupla-face. A firmeza da polpa dos frutos foi avaliada com auxílio do penetrômetro manual Fruit Pressure Test FT 327, com ponteira cilíndrica de $4 \mathrm{~mm}$ de diâmetro. Foram feitas três leituras por bandeja: duas nas extremidades e uma na região central, de diferentes pedaços. O teor de sólidos solúveis foi determinado por leitura direta em refratômetro manual Atago $n^{\circ} 1$, de acordo com o método no 932.12 da AOAC (HORWITZ, 2005). O pH foi determinado em potenciômetro Tecnal TEC3-MP, segundo o método 981.12 da AOAC (HORWITZ, 2005), e a acidez titulável, expressa em porcentual de ácido cítrico, segundo o método 942.15 da AOAC (HORWITZ, 2005).

\subsection{Avaliação instrumental da cor}

Para a coloração da polpa, utilizou-se um colorímetro minolta Chroma Meter CR 400b, calibrado em superfície de porcelana branca. Para maior representatividade da unidade experimental, foram efetuadas duas leituras nas extremidades de um mesmo pedaço de mamão e uma terceira leitura na região central do outro pedaço contido na bandeja. As leituras dos parâmetros $L$ (Luminosidade), $a^{*}$ e b* permitiram calcular o ângulo Hue, ou seja, tonalidade ou matiz e o Croma ou saturação da cor. O ângulo Hue equivale ao [arco tangente $\left.\left(b^{*} / a^{*}\right)\right]$ e o Croma ao $\left[\left(a^{* 2}+b^{* 2}\right)^{1 / 2}\right]$, conforme Minolta (1994).

\subsection{Avaliação sensorial}

Amostras de mamões MP foram avaliadas por uma equipe de 30 provadores não treinados, constituída por estudantes e funcionários do campus universitário, na faixa etária entre 18 e 50 anos. As quatro amostras, a $12^{\circ} \mathrm{C}$, foram servidas em pequenos potes descartáveis brancos, os quais foram dispostos de modo aleatorizado em bandeja de plástico branco, sob iluminação natural. Foi aplicado o teste de escala hedônica estruturada de nove pontos ( $1=$ desgostei extremamente; $5=$ nem gostei/nem desgostei; 9 = gostei extremamente) para avaliar a aceitação do produto. Na medida em que as amostras controle e as revestidas foram apresentadas simultaneamente aos provadores, adotou-se um delineamento de blocos completos casualizados. Os atributos avaliados sequencialmente foram aparência, aroma, sabor e textura (MEILGAARD et al., 1999). 


\subsection{Análise estatística}

Os resultados das análises físicas, físico-químicas e sensoriais nos mamões MP foram submetidos à análise de variância e comparação de médias pelo teste de Tukey (5\%), com auxílio do software WinSTAT® versão 2.11 (MACHADO e CONCEIÇÃO, 2003).

\section{Resultados e discussão}

\subsection{Análises microbiológicas}

Não foi detectada a presença de Salmonella nos frutos dos diversos tratamentos durante o armazenamento e as contagens de coliformes termotolerantes foram inferiores a 10 UFC.g . $^{-1}$. As amostras com e sem revestimento, portanto, atendem à legislação brasileira, que estabelece ausência de Salmonella em $25 \mathrm{~g}$ de amostra e, no máximo, $5 \times 10^{2}$ UFC de coliformes termotolerantes em $1 \mathrm{~g}$ de fruta fresca (BRASIL, 2001).

Em todos os tratamentos e dias, as contagens de bactérias psicrotróficas foram inferiores a 10 UFC.g ${ }^{-1}$, indicando boas condições higiênicas dos produtos.

Os resultados das análises de coliformes totais e de bolores e leveduras nos mamões são apresentados na Tabela 1

A presença de películas (AA, AS e CMC) interferiu no desenvolvimento de coliformes totais, sendo que essas amostras apresentaram contagens inferiores às das amostras controle durante os 15 dias de armazenamento. Vários polissacarídeos e derivados têm sido empregados como coberturas comestíveis com boas propriedades bactericidas e fungistáticas. Uma das hipóteses para a atividade antimicrobiana dos revestimentos à base de

Tabela 1. Resultados das análises microbiológicas dos mamões submetidos aos diferentes tratamentos ${ }^{*}$ e armazenados a $5^{\circ} \mathrm{C}$.

\begin{tabular}{|c|c|c|c|c|}
\hline Dias & Controle & AA $3 \%$ & AS $0,5 \%$ & CMC $0,25 \%$ \\
\hline \multicolumn{5}{|c|}{ Coliformes totais (UFC. g $^{-1}$ ) } \\
\hline $1^{\circ}$ & $<10^{2}$ & $<10$ & $<10$ & $<10$ \\
\hline $3^{\circ}$ & $<10^{2}$ & $<10$ & $<10$ & $<10$ \\
\hline $6^{\circ}$ & $<10^{2}$ & $<10$ & $<10$ & $<10$ \\
\hline $9^{\circ}$ & $<10^{2}$ & $<10$ & $<10$ & $<10$ \\
\hline $12^{\circ}$ & $5 \times 10^{2}$ & $<10$ & $<10$ & $<10$ \\
\hline $15^{\circ}$ & $5 \times 10^{2}$ & $<10$ & $<10$ & $<10$ \\
\hline \multicolumn{5}{|c|}{ Bolores e leveduras (UFC. $\mathbf{g}^{-1}$ ) } \\
\hline $1^{\circ}$ & $<10$ & $<10$ & $<10$ & $<10$ \\
\hline $3^{\circ}$ & $<10$ & $<10$ & $<10$ & $<10$ \\
\hline $6^{\circ}$ & $<10$ & $<10$ & $<10$ & $<10$ \\
\hline $9^{\circ}$ & $<10$ & $<10$ & $<10$ & $<10$ \\
\hline $12^{\circ}$ & $5,6 \times 10^{4}$ & $5,6 \times 10^{4}$ & $5,6 \times 10^{4}$ & $5,6 \times 10^{4}$ \\
\hline $15^{\circ}$ & $5,6 \times 10^{4}$ & $5,6 \times 10^{4}$ & $5,6 \times 10^{4}$ & $5,6 \times 10^{4}$ \\
\hline
\end{tabular}

${ }^{*} \mathrm{AA}=$ amido de arroz; $\mathrm{AS}=$ alginato de sódio; $\mathrm{CMC}=$ carboximetilcelulose . polissacarídeos é de que as moléculas do polímero se entrelaçariam no entorno das bactérias, gerando uma barreira física para a penetração de nutrientes essenciais para o crescimento microbiano (ASSIS et al. 2009).

Com relação à contagem de bolores e leveduras, não houve diferença entre as amostras controle e as revestidas. Nos dias 12 e 15, entretanto, houve elevação considerável do número desses microrganismos em todos os tratamentos. Embora não haja limites fixados pela legislação atual, tal elevação se mostra negativa, indicando problemas com o tempo de estocagem. Por outro lado, Vitti et al. (2004) estabeleceram $10^{5}$ como limite máximo permitido para esses microrganismos, porque, acima desse limite, podem tornar o alimento impróprio para o consumo humano.

\subsection{Análises físicas e físico-químicas}

As concentrações de $\mathrm{CO}_{2}$ no interior das embalagens e a firmeza de mamões MP são apresentadas na Tabela 2.

Valores seguidos de mesma letra minúscula na coluna e maiúscula na linha não diferem significativamente no nível de $5 \%$.

$\mathrm{O}$ acúmulo de $\mathrm{CO}_{2}$ no interior das embalagens que continham mamões recobertos com AA foi significativamente menor do que naqueles recobertos com CMC nos $12^{\circ}$ e $15^{\circ}$ dias, indicando menor respiração. A estrutura formada pela retrogradação das moléculas de amilose apresenta boas propriedades de barreira ao $\mathrm{O}_{2}$. Essa barreira do amido de arroz, provavelmente, limitou o acesso do $\mathrm{O}_{2}$ aos frutos, inibindo a atividade respiratória dos mesmos.

Tabela 2. Médias e desvios padrões das concentrações de $\mathrm{CO}_{2}$ e firmeza de mamões submetidos aos diferentes tratamentos ${ }^{*}$ e armazenados a $5^{\circ} \mathrm{C}$

\begin{tabular}{|c|c|c|c|c|}
\hline Dias & Controle & AA 3\% & AS $0,5 \%$ & CMC $0,25 \%$ \\
\hline \multicolumn{5}{|c|}{ Concentração de $\mathrm{CO}_{2}$ no interior das embalagens (\%) } \\
\hline $1^{\circ}$ & $1,8 \pm 0,1^{\text {aa }}$ & $1,7 \pm 0,1^{\mathrm{aA}}$ & $1,5 \pm 0,1^{\text {aа }}$ & $1,6 \pm 0,1^{\text {aA }}$ \\
\hline $3^{\circ}$ & $3,1 \pm 0,2^{\text {ba }}$ & $2,8 \pm 0,7^{\mathrm{bA}}$ & $3,1 \pm 0,1^{\text {ba }}$ & $3,4 \pm 0,3^{\mathrm{bA}}$ \\
\hline $6^{\circ}$ & $5,1 \pm 1,0^{\text {ca }}$ & $3,8 \pm 2,0^{\text {bca }}$ & $5,0 \pm 0,4^{c a}$ & $6,0 \pm 0,7^{\mathrm{CA}}$ \\
\hline $9^{\circ}$ & $5,8 \pm 1,7^{\text {ca }}$ & $4,1 \pm 2,6^{\text {bca }}$ & $5,9 \pm 0,7^{\text {ca }}$ & $7,2 \pm 0,7^{\text {ca }}$ \\
\hline $12^{\circ}$ & $6,4 \pm 2,3^{\mathrm{cab}}$ & $4,2 \pm 2,9^{b c b}$ & $6,6 \pm 0,8^{\mathrm{cab}}$ & $7,8 \pm 0,9$ ca \\
\hline $15^{\circ}$ & $7,7 \pm 3,2^{\mathrm{cab}}$ & $4,9 \pm 3,9^{с B}$ & $7,8 \pm 1,3^{\mathrm{cab}}$ & $9,5 \pm 1,1^{\text {ca }}$ \\
\hline \multicolumn{5}{|c|}{ Firmeza (N) } \\
\hline $1^{\circ}$ & $6,2 \pm 1,7^{\mathrm{aba}}$ & $5,3 \pm 0,9^{a b a}$ & $5,1 \pm 1,0^{\text {ba }}$ & $5,6 \pm 1,5^{\text {aba }}$ \\
\hline $3^{\circ}$ & $4,0 \pm 0,8^{c a}$ & $3,7 \pm 1,5^{\text {bca }}$ & $3,8 \pm 0,6^{\text {bca }}$ & $4,6 \pm 1,0^{\text {ba }}$ \\
\hline $6^{\circ}$ & $5,4 \pm 1,2^{\text {bca }}$ & $5,4 \pm 1,8^{\mathrm{aba}}$ & $4,0 \pm 1,0^{\text {bca }}$ & $5,3 \pm 0,5^{\text {aba }}$ \\
\hline $9^{\circ}$ & $8,3 \pm 1,5^{\text {aа }}$ & $5,4 \pm 1,3^{a b b}$ & $8,4 \pm 3,5^{\text {aa }}$ & $7,1 \pm 1,7^{\text {aab }}$ \\
\hline $12^{\circ}$ & $5,3 \pm 1,5^{\mathrm{bcb}}$ & $6,1 \pm 2,6^{\mathrm{ab}}$ & $11,0 \pm 2,7^{\text {aа }}$ & $5,3 \pm 1,5^{a b b}$ \\
\hline $15^{\circ}$ & $4,1 \pm 2,4^{\mathrm{cb}}$ & $2,7 \pm 1,1^{c b}$ & $2,9 \pm 1,1^{c b}$ & $6,1 \pm 1,1^{\text {aba }}$ \\
\hline
\end{tabular}

${ }^{*} \mathrm{AA}=$ amido de arroz; $\mathrm{AS}=$ alginato de sódio; $\mathrm{CMC}=$ carboximetilcelulose. 
Em relação ao tempo de estocagem, em todos os tratamentos observou-se tendência a acumular $\mathrm{CO}_{2}$ no interior das embalagens em função do processo de respiração do fruto. O aumento mais acentuado ocorreu entre $01^{\circ}$ e o $6^{\circ}$ dia, um comportamento típico de frutos climatéricos. A partir do $9^{\circ}$ dia, os teores de $\mathrm{CO}_{2}$ não variaram.

Até $\circ 6^{\circ}$ dia de estocagem, os mamões MP não apresentaram diferença significativa entre os tratamentos quanto à firmeza. No $9^{\circ}$ dia, entretanto, os mamões com AA apresentaram menor firmeza que os frutos do controle e com AS, como uma consequência de terem mantido a média em relação ao $6^{\circ}$ dia. No $12^{\circ}$ dia, as amostras com AS apresentaram maior firmeza que os demais tratamentos.

As médias de firmeza se mostraram variáveis com o tempo de estocagem; entretanto, observa-se que os tratamentos apresentaram valores maiores, embora não significativo em alguns casos, até o $9^{\circ}$ ou $12^{\circ}$ dia, e posterior redução da resistência dos tecidos. No $15^{\circ}$ dia, com exceção do tratamento com CMC, os tratamentos apresentaram decréscimo da firmeza, resultante do avanço do processo natural de amaciamento e senescência dos frutos.

O aumento da firmeza pode decorrer da perda de umidade, levando à formação de tecido superficial mais resistente. No entanto, a presença de exsudados não foi constatada no presente estudo. Outro fator que justificaria a elevação da resistência da polpa seria a lignificação provocada pela "cicatrização de ferida", processo induzido pelas injúrias causadas pelas operações do processamento mínimo (JACOMINO et al., 2008). Note-se que, mais ao final, dentre as causas principais da perda da firmeza da polpa do mamão, está a degradação de protopectina da lamela média e da parede celular primária, e o aumento da pectina solúvel.

As médias de sólidos solúveis, acidez titulável e pH dos mamões MP são apresentados na Tabela 3.

A composição em sólidos solúveis dos mamões MP mostra que, dentro de quase todos os períodos, os revestimentos aplicados resultaram em menores teores de sólidos solúveis que o controle. Pode ser que a imersão dos frutos nessas soluções filmogênicas tenha ocasionado lixiviação dos sólidos solúveis. Tais diferenças entre os tratamentos com e sem película se acentuaram após o $9^{\circ}$ dia de armazenamento. Fontes et al. (2008) avaliaram películas em maçãs Royal Gala MP armazenadas em câmara fria $\left(2^{\circ} \mathrm{C}\right.$ e $40 \%$ UR) e também constataram que os produtos revestidos (amido e dextrina) apresentaram menores teores de sólidos solúveis que o controle e que as diferenças entre tratamentos se acentuaram no $13^{\circ}$ dia.

O tempo de estocagem alterou significativamente o teor de sólidos solúveis dos mamões MP dentro de cada tratamento. Os frutos controle foram os menos

Tabela 3. Médias e desvios padrões dos sólidos solúveis, acidez titulável e pH nos mamões submetidos aos diferentes tratamentos* e armazenados a $5^{\circ} \mathrm{C}$.

\begin{tabular}{|c|c|c|c|c|}
\hline Dias & Controle & AA $3 \%$ & AS $0,5 \%$ & CMC $0,25 \%$ \\
\hline \multicolumn{5}{|c|}{ Sólidos solúveis ( ${ }^{\circ}$ Brix) } \\
\hline $1^{\circ}$ & $11,5 \pm 0,3^{\mathrm{aA}}$ & $11,0 \pm 0^{\mathrm{aB}}$ & $11,0 \pm 0^{\mathrm{aB}}$ & $11,2 \pm 0,2^{\mathrm{aAB}}$ \\
\hline $3^{\circ}$ & $11,7 \pm 0,5^{\mathrm{aA}}$ & $10,6 \pm 0,4^{\mathrm{aB}}$ & $10,6 \pm 0,5^{\mathrm{abB}}$ & $10,5 \pm 0,3^{\mathrm{bB}}$ \\
\hline $6^{\circ}$ & $11,5 \pm 0,4^{\mathrm{aA}}$ & $10,1 \pm 0,3^{\mathrm{bB}}$ & $10,5 \pm 0,2^{\mathrm{bB}}$ & $10,3 \pm 0,1^{\mathrm{bcB}}$ \\
\hline $9^{\circ}$ & $10,8 \pm 0,1^{\mathrm{bA}}$ & $9,7 \pm 0,1^{\mathrm{cdB}}$ & $9,5 \pm 0,4^{\mathrm{cB}}$ & $9,6 \pm 0,4^{\mathrm{dB}}$ \\
\hline $12^{\circ}$ & $10,7 \pm 0,3^{\mathrm{bA}}$ & $9,3 \pm 0,2^{\mathrm{dc}}$ & $8,9 \pm 0,5^{\mathrm{dD}}$ & $9,8 \pm 0,1^{\mathrm{cdB}}$ \\
\hline $15^{\circ}$ & $10,4 \pm 0,1^{\mathrm{bA}}$ & $10,0 \pm 0,3^{\mathrm{bcA}}$ & $9,6 \pm 0,2^{\mathrm{cB}}$ & $9,5 \pm 0,4^{\mathrm{dB}}$ \\
\hline \multicolumn{5}{|c|}{ pH } \\
\hline $1^{\circ}$ & $4,8 \pm 0,1^{\text {ca }}$ & $4,7 \pm 0,1^{\text {ca }}$ & $4,8 \pm 0,1^{\text {cda }}$ & $4,7 \pm 0^{\text {dea }}$ \\
\hline $3^{\circ}$ & $5,1 \pm 0^{\text {aba }}$ & $5,1 \pm 0^{\text {aa }}$ & $5,1 \pm 0^{\text {aa }}$ & $5,1 \pm 0^{\text {aa }}$ \\
\hline $6^{\circ}$ & $5,0 \pm 0^{\mathrm{ba}}$ & $4,9 \pm 0,1^{\mathrm{ba}}$ & $4,9 \pm 0^{\text {bca }}$ & $5,0 \pm 0,1^{\text {ba }}$ \\
\hline $9^{\circ}$ & $5,0 \pm 0,1^{\text {ba }}$ & $4,7 \pm 0,1^{\mathrm{cb}}$ & $5,1 \pm 0^{\text {aa }}$ & $4,8 \pm 0^{c d b}$ \\
\hline $12^{\circ}$ & $5,2 \pm 0^{\text {aa }}$ & $4,9 \pm 0,3^{\mathrm{bb}}$ & $4,9 \pm 0,1^{\mathrm{bb}}$ & $4,8 \pm 0^{c b}$ \\
\hline $15^{\circ}$ & $5,0 \pm 0,1^{\text {aba }}$ & $4,5 \pm 0,1^{d c}$ & $4,7 \pm 0^{\mathrm{db}}$ & $4,6 \pm 0,2^{\mathrm{eb}}$ \\
\hline \multicolumn{5}{|c|}{ Acidez titulável (g ácido cítrico 100 g $^{-1}$ ) } \\
\hline $1^{\circ}$ & $0,190 \pm 0^{\text {cda }}$ & $0,125 \pm 0^{c b}$ & $0,127 \pm 0^{c b}$ & $0,127 \pm 0^{c b}$ \\
\hline $3^{\circ}$ & $0,254 \pm 0^{\mathrm{aba}}$ & $0,190 \pm 0^{\mathrm{bb}}$ & $0,189 \pm 0^{\mathrm{bb}}$ & $0,238 \pm 0,02^{\mathrm{ba}}$ \\
\hline $6^{\circ}$ & $0,161 \pm 0,03^{\mathrm{da}}$ & $0,141 \pm 0,02^{\text {ca }}$ & $0,162 \pm 0,03^{\mathrm{ba}}$ & $0,155 \pm 0,03^{c a}$ \\
\hline $9^{\circ}$ & $0,211 \pm 0,04^{\text {bcab }}$ & $0,204 \pm 0,05^{\text {bab }}$ & $0,191 \pm 0,04^{\mathrm{bb}}$ & $0,240 \pm 0,04^{\mathrm{ba}}$ \\
\hline $12^{\circ}$ & $0,308 \pm 0,01^{\mathrm{aab}}$ & $0,331 \pm 0,05^{\text {aa }}$ & $0,266 \pm 0,04^{\mathrm{ab}}$ & $0,310 \pm 0,02^{\mathrm{aab}}$ \\
\hline $15^{\circ}$ & $0,314 \pm 0,05^{\mathrm{aa}}$ & $0,191 \pm 0,04^{\mathrm{bb}}$ & $0,302 \pm 0,04^{\text {aa }}$ & $0,301 \pm 0,02^{\text {aa }}$ \\
\hline
\end{tabular}

${ }^{*} \mathrm{AA}=$ amido de arroz; $\mathrm{AS}=$ alginato de sódio; $\mathrm{CMC}=$ carboximetilcelulose. Valores seguidos de mesma letra minúscula na coluna e maiúscula na linha não diferem significativamente no nível de 5\%. 
Efeito de revestimentos comestíveis na conservação de mamões minimamente processados

TRIGO J. M. et al.

afetados, tendo ocorrido redução significativa no $9^{\circ}$ dia. Nos demais tratamentos, as oscilações foram maiores e constatadas em períodos anteriores. A redução nos teores de sólidos pode ser consequência do consumo destes pela respiração dos frutos ao longo do período de armazenamento. Os frutos com CMC, que apresentaram maiores acúmulos de $\mathrm{CO}_{2}$, foram os que já no $3^{\circ}$ dia apresentaram diferenças significativas de sólidos solúveis em relação ao $1^{\circ}$ dia.

Apesar de não terem sido detectadas diferenças significativas de acidez titulável nos $9^{\circ}$ e $12^{\circ}$ dias, os frutos com AA, AS e CMC apresentaram menores valores de $\mathrm{pH}$ que o controle a partir do $9^{\circ} \mathrm{dia}$, indicando que, ao final do armazenamento, pode ter havido anaerobiose no interior dos mamões, causada pelas próprias películas, que não teriam permitido a passagem do $\mathrm{CO}_{2}$ do interior dos tecidos para o interior das embalagens, resultando na acidificação dos frutos.

A acidez titulável dos diferentes tratamentos mostrou-se bastante variável durante o período avaliado. Foi observado, entretanto, que nos $1^{\circ}$ e $3^{\circ}$ dias, os frutos com AA, AS e CMC apresentaram menores valores que o controle, indicando que o uso dos revestimentos pode ter minimizado a respiração climatérica. No climatério respiratório, as reações relacionadas aos processos de amadurecimento e senescência são aceleradas e, com isto, a liberação de ácidos orgânicos provenientes dessas reações pode aumentar a acidez do meio. Pereira et al. (2006) avaliaram o amadurecimento de frutos de mamão Formosa em temperatura ambiente e também relataram grandes oscilações da acidez titulável, porém com aumento mais rápido nos frutos controle do que nos revestidos com fécula.

O tempo de estocagem alterou significativamente a acidez titulável e o pH dos mamões MP dentro de cada tratamento. Apesar das oscilações, houve tendência de aumento da acidez. Além da possível formação de ácido galacturônico, proveniente da degradação das pectinas, o teor de $\mathrm{CO}_{2}$ que foi se acumulando no interior das embalagens e o desenvolvimento de microrganismos ao final do armazenamento podem ter contribuído para a acidificação dos frutos. $\mathrm{O} \mathrm{pH}$ do controle foi o que se manteve mais estável durante o período avaliado.

\subsection{Cor}

A luminosidade é um parâmetro que pode variar do zero (preto) ao 100 (branco) e os mamões MP, no presente estudo, apresentaram luminosidade entre 48,2 e 62,2 (Tabela 4).

Os frutos tratados com CMC tenderam a apresentar as maiores médias de L, ou seja, mamões mais claros que os demais tratamentos. Tais valores, entretanto, somente diferiram significativamente do controle no $3^{\circ}$

Tabela 4. Médias e desvios padrões de luminosidade, ângulo Hue e croma dos mamões submetidos aos diferentes tratamentos* e armazenados a $5{ }^{\circ} \mathrm{C}$

\begin{tabular}{|c|c|c|c|c|}
\hline Dias & Controle & AA $3 \%$ & AS $0,5 \%$ & CMC $0,25 \%$ \\
\hline \multicolumn{5}{|c|}{ Luminosidade } \\
\hline $1^{\circ}$ & $52,5 \pm 8,2^{\mathrm{bab}}$ & $52,1 \pm 6,8^{\mathrm{bab}}$ & $48,2 \pm 8,7^{\mathrm{bb}}$ & $57,2 \pm 5,9^{a a}$ \\
\hline $3^{\circ}$ & $54,8 \pm 2,0^{a b b}$ & $56,2 \pm 3,1^{\mathrm{abb}}$ & $55,6 \pm 5,1^{\mathrm{ab}}$ & $62,2 \pm 3,9^{\text {aа }}$ \\
\hline $6^{\circ}$ & $56,2 \pm 5,1^{\mathrm{aba}}$ & $59,4 \pm 4,4^{\mathrm{aa}}$ & $58,0 \pm 3,7^{\text {aа }}$ & $60,9 \pm 3,8^{\text {aа }}$ \\
\hline $9^{\circ}$ & $57,1 \pm 3,6^{\mathrm{aba}}$ & $55,9 \pm 3,5^{\mathrm{aba}}$ & $57,0 \pm 5,4^{\text {aa }}$ & $59,5 \pm 4,2^{\text {aa }}$ \\
\hline $12^{\circ}$ & $57,5 \pm 3,2^{\mathrm{aba}}$ & $58,7 \pm 2,7^{\mathrm{aba}}$ & $57,7 \pm 4,5^{\text {aа }}$ & $58,8 \pm 2,8^{a a}$ \\
\hline $15^{\circ}$ & $59,6 \pm 2,6^{a a b}$ & $55,6 \pm 3,0^{a b b}$ & $54,4 \pm 6,7^{a b b}$ & $61,0 \pm 3,7^{\text {aа }}$ \\
\hline \multicolumn{5}{|c|}{ Hue } \\
\hline $1^{\circ}$ & $56,9 \pm 1,8^{b a}$ & $58,3 \pm 2,2^{\mathrm{ba}}$ & $56,3 \pm 3,1^{\mathrm{ba}}$ & $59,1 \pm 1,2^{\mathrm{aa}}$ \\
\hline $3^{\circ}$ & $56,7 \pm 1,6^{\mathrm{bb}}$ & $58,8 \pm 2,6^{a b a b}$ & $59,1 \pm 2,1^{\mathrm{abab}}$ & $60,4 \pm 1,6^{\text {aa }}$ \\
\hline $6^{\circ}$ & $58,1 \pm 3,1^{a b b}$ & $61,9 \pm 3,6^{\text {aa }}$ & $60,7 \pm 1,9^{a a b}$ & $60,4 \pm 1,9^{a a b}$ \\
\hline $9^{\circ}$ & $59,4 \pm 3,3^{\mathrm{aba}}$ & $60,6 \pm 2,4^{\mathrm{aba}}$ & $59,2 \pm 3,0^{\mathrm{aba}}$ & $59,3 \pm 2,3^{\text {аa }}$ \\
\hline $12^{\circ}$ & $59,0 \pm 2,3^{a b a}$ & $59,4 \pm 1,7^{\text {aba }}$ & $60,7 \pm 2,8^{\text {aа }}$ & $58,4 \pm 1,2^{\text {aa }}$ \\
\hline $15^{\circ}$ & $60,2 \pm 1,5^{\mathrm{aa}}$ & $60,6 \pm 1,5^{\mathrm{aba}}$ & $59,6 \pm 2,3^{\text {aа }}$ & $60,6 \pm 2,4^{\text {aa }}$ \\
\hline \multicolumn{5}{|c|}{ Croma } \\
\hline $1^{\circ}$ & $42,6 \pm 5,9^{a a b}$ & $44,0 \pm 3,4^{\text {aa }}$ & $39,4 \pm 5,7^{a b}$ & $45,1 \pm 3,2^{\mathrm{aa}}$ \\
\hline $3^{\circ}$ & $45,0 \pm 4,2^{\mathrm{aa}}$ & $41,7 \pm 2,3^{\mathrm{aba}}$ & $43,0 \pm 3,1^{\text {aa }}$ & $42,6 \pm 3,5^{\text {aа }}$ \\
\hline $6^{\circ}$ & $44,4 \pm 3,2^{\text {aa }}$ & $42,5 \pm 2,1^{\mathrm{aba}}$ & $41,9 \pm 1,5^{\text {aа }}$ & $42,2 \pm 1,6^{\text {aa }}$ \\
\hline $9^{\circ}$ & $43,4 \pm 2,9^{a a}$ & $38,3 \pm 2,7^{\mathrm{bb}}$ & $40,4 \pm 2,3^{a a b}$ & $43,1 \pm 3,9^{\text {aа }}$ \\
\hline $12^{\circ}$ & $43,0 \pm 2,7^{\text {aa }}$ & $40,7 \pm 2,6^{\mathrm{aba}}$ & $39,9 \pm 3,2^{\text {aа }}$ & $41,6 \pm 1,9^{\text {aа }}$ \\
\hline $15^{\circ}$ & $41,8 \pm 2,2^{a a b}$ & $44,1 \pm 1,1^{\text {aa }}$ & $40,0 \pm 3,8^{a b}$ & $42,4 \pm 3,1^{\mathrm{aab}}$ \\
\hline
\end{tabular}

${ }^{*} \mathrm{AA}=$ amido de arroz; $\mathrm{AS}=$ alginato de sódio; $\mathrm{CMC}=$ carboximetilcelulose. Valores seguidos de mesma letra minúscula na coluna e maiúscula na linha não diferem significativamente no nível de $5 \%$. 
dia de armazenamento. A solução filmogênica da CMC é mais clara que as demais, o que pode ter colaborado para tal média de L. Por outro lado, as polpas com AS apresentaram as menores médias (mais escuras) dentre os tratamentos nos $1^{\circ}$ e $15^{\circ}$ dias, não diferindo estatisticamente do controle. E essa tendência ao escurecimento pode ter ocorrido pela própria coloração da solução de revestimento, que é levemente marrom.

As menores médias de luminosidade dos mamões com AA em relação ao tratamento com $\mathrm{CMC}$ nos $3^{\circ} \mathrm{e}$ $15^{\circ}$ dias, possivelmente, decorram da retrogradação do amido, fenômeno que pode elevar a opacidade da película. Após gelatinização do amido e o armazenamento sob baixas temperaturas, pode ocorrer a recristalização das cadeias de amilose e amilopectina (JANG e PYUN, 1997).

O tempo de estocagem não afetou significativamente a luminosidade dos mamões tratados com CMC. Nos demais tratamentos, houve variabilidades significativas, com tendências mais definidas à elevação no decorrer do tempo apenas para os frutos controle.

Os valores do ângulo Hue variaram de 56,3 a 61,9 (Tabela 4). De acordo com o sistema CIELAB, se o ângulo estiver entre $0^{\circ}$ e $90^{\circ}$, quanto maior este for, mais amarelo é o fruto, e, quanto menor for, mais vermelho é o fruto. Valores maiores que os do controle foram obtidos para os tratamentos com $\mathrm{CMC}$ e $\mathrm{AA}$, nos $3^{\circ}$ e $6^{\circ}$ dias, respectivamente. A imersão dos frutos nas soluções filmogênicas pode ter lixiviado parte dos pigmentos carotenoides, deixando-os menos alaranjados. Segundo Ambrósio et al. (2006), os carotenoides são compostos hidrofóbicos, lipofílicos, insolúveis em água e solúveis em solventes, como acetona, álcool e clorofórmio. Considerando-se que às soluções filmogênicas de CMC e AA, foi adicionado sorbitol, um poliálcool, os pigmentos podem ter sido "lavados" dos frutos, fato demonstrado pela coloração alaranjada detectada visualmente nas soluções filmogênicas após imersão dos pedaços de mamão.

O tempo de estocagem não afetou significativamente o ângulo Hue dos mamões tratados com CMC. Para os frutos revestidos com AA e AS, foi constatado aumento significativo no $6^{\circ}$ dia, enquanto que, para o controle, houve variabilidade significativa somente no $15^{\circ}$ dia.

Os frutos com AS apresentaram menor média de croma (menor intensidade da coloração alaranjada) do que as amostras com AA e CMC, no $1^{\circ}$ dia (Tabela 4), provavelmente por causa do aspecto levemente marrom da solução filmogênica do AS. No $9^{\circ}$ dia, as amostras com AA apresentaram a menor cromaticidade, possivelmente influenciada pela coloração da película, que pode se tornar mais esbranquiçada em função da retrogradação no tempo de estocagem refrigerada. A análise dos períodos dentro de cada tratamento somente evidenciou alteração significativa para os mamões recobertos com $A A$.

\subsection{Avaliação sensorial}

Os resultados obtidos no teste de escala hedônica dos mamões MP estão apresentados na Tabela 5.

Os atributos de aparência, aroma e sabor dos mamões foram pouco afetados pelos revestimentos e bem aceitos pelos provadores, sendo que as amostras foram classificadas entre "gostei ligeiramente" e "gostei muito". Já na avaliação da textura, o controle recebeu classificação entre "gostei regularmente" e "gostei muito", enquanto a das amostras com revestimentos situou-se entre "gostei ligeiramente" e "gostei muito".

A avaliação sensorial não evidenciou diferença significativa entre os produtos com ou sem películas para os atributos de aroma, sabor e textura. Para aparência, entretanto, o produto com AS alcançou média superior ao controle no $3^{\circ}$ dia de estocagem.

As diferenças constatadas na avaliação instrumental da cor entre frutos revestidos e não revestidos não foram percebidas pelos provadores na avaliação da aparência.

O tempo de armazenamento influenciou significativamente mais os atributos do tratamento AA. As amostras com esse revestimento apresentaram redução de notas para a aparência, o sabor e a textura durante $\mathrm{o}$ armazenamento dos mamões, sendo diferentes estatisticamente nos dias 1 e 15. Observações feitas pelos provadores nas fichas do teste dos últimos dias de armazenamento foram de que esses produtos apresentavam aspecto ligeiramente esbranquiçado e menor firmeza das amostras.

As notas significativamente menores atribuídas ao sabor do mamão controle e com AA e AS no $15^{\circ}$ dia foram, segundo os provadores, decorrentes do sabor amargo das amostras. Esse fato pode ser indicativo de anaerobiose no interior dos tecidos, estimulando o crescimento de bactérias homo e heterofermentativas e leveduras, as quais produzem ácidos orgânicos, etanol e ésteres voláteis, responsáveis pela depreciação do sabor (BEAUDRY, 2000).

Os mamões tratados com CMC não apresentaram variação significativa para os atributos sensoriais com o tempo de armazenamento. Diferentemente, as amostras controle apresentaram variação de notas para aparência, embora sem sequência definida no tempo, e redução de notas de sabor no $15^{\circ}$ dia.

\section{Conclusões}

$\mathrm{Na}$ medida em que a maioria dos efeitos positivos das coberturas ocorreu nos $12^{\circ}$ e $15^{\circ}$ dias e, 
Efeito de revestimentos comestíveis na conservação de mamões minimamente processados

TRIGO J. M. et al.

Tabela 5. Médias de notas da análise sensorial dos diferentes tratamentos ${ }^{\star}$ de mamão, durante armazenamento a $5^{\circ} \mathrm{C}$.

\begin{tabular}{|c|c|c|c|c|c|c|}
\hline \multirow{3}{*}{ Tratamento } & \multicolumn{6}{|c|}{ Dias de armazenamento } \\
\hline & $1^{\circ}$ & $3^{\circ}$ & $6^{\circ}$ & $9^{\circ}$ & $12^{\circ}$ & $15^{\circ}$ \\
\hline & \multicolumn{6}{|c|}{ Aparência } \\
\hline Controle & $6,85^{\mathrm{aAB}}$ & $6,61^{\mathrm{bAB}}$ & $7,15^{\mathrm{aAB}}$ & $6,21^{\mathrm{aB}}$ & $7,63^{\mathrm{aA}}$ & $7,15^{\mathrm{aAB}}$ \\
\hline AA 3\% & $7,43^{\mathrm{aA}}$ & $7,15^{\mathrm{abAB}}$ & $7,29^{\mathrm{aAB}}$ & $6,69^{\mathrm{aAB}}$ & $7,22^{\mathrm{aAB}}$ & $6,04^{\mathrm{aB}}$ \\
\hline AS $0,5 \%$ & $7,00^{\mathrm{aA}}$ & $7,82^{\mathrm{aA}}$ & $7,22^{\mathrm{aA}}$ & $7,29^{\mathrm{aA}}$ & $7,63^{\mathrm{aA}}$ & $6,93^{\mathrm{aA}}$ \\
\hline \multirow[t]{2}{*}{ CMC $0,25 \%$} & $7,22^{\mathrm{aA}}$ & $7,29 \mathrm{abA}$ & $7,56^{\mathrm{aA}}$ & $6,77^{\text {aA }}$ & $6,85^{\mathrm{aA}}$ & $6,93^{\mathrm{aA}}$ \\
\hline & \multicolumn{6}{|c|}{ Aroma } \\
\hline Controle & $7,43^{\mathrm{aA}}$ & $6,69^{\mathrm{aA}}$ & $7,15^{\mathrm{aA}}$ & $6,77^{\mathrm{aA}}$ & $7,76^{\mathrm{aA}}$ & $6,93^{\mathrm{aA}}$ \\
\hline AA 3\% & $7,36^{\mathrm{aA}}$ & $7,00^{\mathrm{aA}}$ & $7,29^{\mathrm{aA}}$ & $7,43^{\mathrm{aA}}$ & $7,29^{\mathrm{aA}}$ & $6,69^{\mathrm{aA}}$ \\
\hline AS $0,5 \%$ & $6,93^{\mathrm{aA}}$ & $7,36^{\mathrm{aA}}$ & $7,56^{\mathrm{aA}}$ & $7,00^{\mathrm{aA}}$ & $7,50^{\mathrm{aA}}$ & $6,37^{\mathrm{aA}}$ \\
\hline \multirow[t]{2}{*}{ CMC 0,25\% } & $7,63^{\mathrm{aA}}$ & $6,85^{\mathrm{aA}}$ & $7,56^{\mathrm{aA}}$ & $7,07^{\mathrm{aA}}$ & $7,07^{\text {aA }}$ & $6,77^{\mathrm{aA}}$ \\
\hline & \multicolumn{6}{|c|}{ Sabor } \\
\hline Controle & $7,56^{\mathrm{aA}}$ & $7,07^{\mathrm{AB}}$ & $7,29^{\mathrm{aAB}}$ & $6,53^{\mathrm{AB}}$ & $7,29^{\mathrm{aAB}}$ & $6,12^{\mathrm{aB}}$ \\
\hline AA 3\% & $7,76^{\mathrm{aA}}$ & $7,36^{\mathrm{aA}}$ & $6,69^{\text {авв }}$ & $7,43^{\mathrm{aA}}$ & $7,00^{\mathrm{aAB}}$ & $5,87^{\mathrm{aB}}$ \\
\hline AS $0,5 \%$ & $7,00^{\mathrm{AaB}}$ & $7,82^{\mathrm{aA}}$ & $7,15^{\mathrm{aAB}}$ & $7,36^{\mathrm{aB}}$ & $7,15^{\mathrm{aAB}}$ & $6,53^{\mathrm{aB}}$ \\
\hline \multirow[t]{2}{*}{ CMC 0,25\% } & $7,07^{\mathrm{aA}}$ & $7,56^{\mathrm{aA}}$ & $7,56^{\mathrm{aA}}$ & $6,93^{\mathrm{aA}}$ & $6,69^{\mathrm{aA}}$ & $6,61^{\text {aA }}$ \\
\hline & \multicolumn{6}{|c|}{ Textura } \\
\hline Controle & $7,69^{\mathrm{aA}}$ & $7,56^{\mathrm{aA}}$ & $7,63^{\mathrm{aA}}$ & $7,15^{\mathrm{aA}}$ & $7,94^{\mathrm{aA}}$ & $7,00^{\mathrm{aA}}$ \\
\hline AA 3\% & $7,88^{\mathrm{aA}}$ & $7,15^{\mathrm{aAB}}$ & $7,50^{\mathrm{aAB}}$ & $7,63^{\mathrm{AB}}$ & $7,07^{\mathrm{AB}}$ & $6,45^{\mathrm{aB}}$ \\
\hline AS $0,5 \%$ & $7,56^{\mathrm{aA}}$ & $7,69^{a A}$ & $7,56^{\mathrm{aA}}$ & $7,63^{\mathrm{aA}}$ & $7,63^{\mathrm{aA}}$ & $6,85^{\mathrm{aA}}$ \\
\hline CMC 0,25\% & $7,56^{\mathrm{aA}}$ & $7,76^{\mathrm{aA}}$ & $7,94^{\mathrm{aA}}$ & $7,36^{\mathrm{aA}}$ & $6,85^{\mathrm{aA}}$ & $7,00^{\mathrm{aA}}$ \\
\hline
\end{tabular}

${ }^{*} \mathrm{AA}$ = amido de arroz; $\mathrm{AS}=$ alginato de sódio; $\mathrm{CMC}=$ carboximetilcelulose. Valores seguidos de mesma letra minúscula na coluna e maiúscula na linha não diferem significativamente no nível de 5\%.

considerando-se o custo da tecnologia relacionado ao preço dos revestimentos, a melhor opção, até nove dias de armazenamento, consiste em fazer apenas uma boa sanitização dos frutos, como feito no controle. No entanto, se o interesse for preservar a vida útil dos mamões por um período maior, até 15 dias, os revestimentos testados podem ser utilizados com resultados satisfatórios, desde que respeitadas as condições de temperatura e umidade utilizadas na presente pesquisa.

\section{Agradecimentos}

À FAPESP, pela concessão de Bolsa de Mestrado e Auxílio à Pesquisa. À Vitopel do Brasil, pela doação do filme de polipropileno, e à Murta Especialidades Químicas, pela doação da carboximetilcelulose.

\section{Referências}

AMBrósio, C. L. B; CAMPOS, F. A. C. S.; FARO, Z. P. Carotenóides como alternativa contra a hipovitaminose $A$. Revista de Nutrição, Campinas, v. 19, n. 2, p. 233-243, 2006. http://dx.doi.org/10.1590/S1415-52732006000200010

ASSIS, O. B. G.; BRITTO, D.; FORATO, L. A. O Uso de Biopolímeros como Revestimentos Comestíveis Protetores para Conservação de Frutas in Natura e minimamente Processadas. São Carlos: Embrapa Instrumentação
Agropecuária, 2009. 23 p. (Embrapa Instrumentação Agropecuária, Boletim de Pesquisa e Desenvolvimento, n. 29).

ASSIS, O. B. G.; FORATO, L. A.; BRITTO, D. Revestimentos comestíveis protetores em frutos minimamente processados. Higiene Alimentar, São Paulo, v. 22, n. 160, p. 99-105, 2008.

BALDWIN, E. A. Surface treatments and edible coatings in food preservation. In: RAHMAN, M. S. (Ed.). Handbook of Food Preservation. 2. ed. Boca Raton: CRC Press, 2007. cap. 21, p. 477-507

BEAUDRY, R. M. Responses of horticultural commodities to low oxygen: limits to the expanded use of modified atmosphere packaging. HortTechnology, Alexandria, v. 10, n. 3, p. 491-500, 2000.

BICALHO, U. O. Vida Útil Pós-colheita de Mamão Submetido a Tratamento com Cálcio e Filme de PVC. 1998. 145 f. Tese (Doutorado em Ciência dos Alimentos)-Universidade Federal de Lavras, Lavras, 1998.

BRASIL. ministério da Agricultura, Pecuária e Abastecimento. Secretaria de Defesa Agropecuária. Instrução normativa n ${ }^{\circ} 62$ de 26 de agosto de 2003. Oficializa os métodos analíticos oficiais para análises microbiológicas para controle de produtos de origem animal e água. Diário Oficial da República Federativa do Brasil, Brasília, DF, 18 set. 2003. Seção 1, p.14.

BRASIL. ministério da Saúde. Agência Nacional de Vigilância Sanitária. Resolução RDC n¹2 de 02 de janeiro de 2001. 
Efeito de revestimentos comestíveis na conservação de mamões minimamente processados

TRIGO J. M. et al.

Regulamento técnico sobre padrões microbiológicos para alimentos. Diário Oficial da República Federativa do Brasil, Brasília, DF, 10 jan. 2001. Seção 1, p. 45-47.

CHITARRA, M. I. F; CHITARRA, A. B. Pós-colheita de Frutas e Hortaliças: Fisiologia e Manuseio. 2. ed. Lavras: UFLA, 2005. $785 \mathrm{p}$.

FNP CONSULTORIA \& COMÉRCIO. Mamão. In: FNP CONSULTORIA \& COMÉRCIO. Agrianual 2011: Anuário da Agricultura Brasileira. São Paulo, 2011. p. 325-332.

FONTES, L. C. B.; SARMENTO, S. B. S.; SPOTO, M. H. F.; DIAS, C. T. S. Conservação de maçã minimamente processada com o uso de películas comestíveis. Ciência e Tecnologia de Alimentos, Campinas, v. 28, n. 4, p. 872-880, 2008. http://dx.doi. org/10.1590/S0101-20612008000400017

HERNÁNDEZ, Y.; LOBO, M. G.; GONZÁLEZ, M. Evaluación de la calidad microbiológica en papaya fresca cortada. In: LOBO, M. G.; GONZÁLEZ, M. (Eds.). Procesado Mínimo de Frutas. La Laguna: Instituto Canario de Investigaciones Agrarias, 2007. p. 99-109.

HORWITZ, W. (Ed.). Official methods of analysis of the Association of Official Analytical Chemists. 18. ed. Gaithersburg, Maryland: AOAC, 2005.

JACOMINO, A. P.; ARRUDA, M. C.; BRON, I. U.; KLUGE, R. A. Transformações bioquímicas em produtos hortícolas após a colheita. In: KOBLITZ, M. G. B. (Ed). Bioquímica de Alimentos: Teoria e Aplicações Práticas. Rio de Janeiro: Guanabara Koogan, 2008. cap. 6, p. 153-190.

JANG, J. K.; PYUN, Y. R. Effect of moisture level on the crystallinity of wheat starch aged at different temperatures. Starch/Stärke, Weinheim, v. 49, n. 7-8, p. 272-277, 1997. http:// dx.doi.org/10.1002/star.19970490705

MACHADO, A. A.; CONCEIÇÃO, A. R. WinStat, sistema para análise estatística para Windows. versão 2.11. Pelotas: UFPel, NIA, 2003.
MEILGAARD, M.; CIVILLE, G. V.; CARR, B. T. Sensory Evaluation Techniques. 3. ed. Boca Raton: CRC Press, 1999. $281 \mathrm{p}$.

MENDONÇA, V.; ABREU, N. A. A.; GURGEL, R. L. S.; FERREIRA, E. A.;ORBES, M. Y.; TOSTA, M. S. Crescimento de mudas de mamoeiro 'Formosa' em substratos com utilização de composto orgânico superfosfato simples. Ciência e Agrotecnologia, Lavras, v. 30, n. 5, p. 861-868, 2006. http://dx.doi.org/10.1590/ S1413-70542006000500006

MINOLTA. Precise Color Communication: Color Control from Feeling to Instrumentation. Osaka: MINOLTA Co. Ltda., 1994. $49 \mathrm{p}$.

PEREIRA, M. E. C.; SILVA, A. S.; BISPO, A. S. R.; SANTOS, D. B.; SANTOS, S. B.; SANTOS, V. J. Amadurecimento de mamão 'Formosa' com revestimento comestível à base de fécula de mandioca. Ciência e Agrotecnologia, Lavras, v. 30, n. 6, p. 1116-1119, 2006. http://dx.doi.org/10.1590/S141370542006000600011

SOUZA, B. S.; DURIGAN, J. F.; DONADON, J. R.; LIMA, M. A. Qualidade e comportamento fisiológico do mamão "Formosa" minimamente processado. Brazilian Journal of Food Technology, Campinas, v. 8, n. 3, p. 243-247, 2005.

TEIXEIRA, G. H. A.; DURIGAN, J. F.; MATTIUZ, B. H.; ROSSI JÚNIOR, O. D. Processamento mínimo de mamão 'Formosa'. Ciência e Tecnologia de Alimentos, v. 21, n. 1, p. 47-50, 2001. http://dx.doi.org/10.1590/S0101-20612001000100011

VITTI, M. C. D.; KLUGE, R. A.; GALLO, C. R.; SCHIAVINATO, M. A.; MORETTI, C. L.; JACOMINO, A. P. Aspectos fisiológicos e microbiológicos de beterraba minimamente processada. Pesquisa Agropecuária Brasileira, Brasília, v. 39, n. 10, p. 1027-1032, 2004. http://dx.doi.org/10.1590/S0100$204 \times 2004001000011$ 